\title{
PENENTUAN SISWA TELADAN PADA SMP NEGERI 29 PADANG DENGAN PEMANFAATAN METODE SIMPLE ADDITIVE WEIGTING ( SAW )
}

\author{
Yanti Yusman ${ }^{1)}$ \\ Dosen Universitas Pembangunan Pancabudi \\ yantiyusman@dosen.pancabudi.ac.id \\ Program Studi : Ilmu Komputer \\ Sri Haryati ${ }^{2)}$ \\ Dosen Politeknik Negeri Banjar Masin \\ iie.minanis3@gmail.com \\ Program Studi : Komputerisasi Akuntansi
}

\begin{abstract}
Abstrak
Tujuan dari Penelitian Mandiri ini adalah untuk penentuan siswa-siswi teladan dengan mengunakan metode SAW seberapa mampu guru-guru di SMP Negeri 29 Padang dalam pennetuan siswa teladan pada sekolah. Metode SAW ini memberikan kemudahan dalam penentuan siapa siswa teladan agar guru mampu membuat suatu keputusan dengan mudah. Sehingga guru dapat memahami bagaimana cara menentukan siswa teladan di SMP Negeri 29 Padang dengan menggunakan Metode SAW
\end{abstract}

Kata Kunci : SPK, SIMPLE ADDITIVE WEIGTING ( SAW ).

\begin{abstract}
The purpose of this Indenpendent Research is to determine model students by using the SAW method of how capable teachers in padang 29 state junior High Scholl are in determining students in schools. The SAW method makes it easy to determine who the model studens are so thet the teacher is able to make decision easily. So the teacher can understand how to determine model students in SMP Negeri 29 Padang by using the Simple additive weigting ( SAW ).
\end{abstract}

Keywords : SPK, Simple Additive Weigting ( SAW ).

\section{I.PENDAHULUHAN}

Dalam Rangka memotivasi siswa-siswi untuk terus berprestasi,SMP Negeri 29 Padang melakukan berbagagai kegiatan untuk mengembangkan potensi diri para siswa melalui pemilihan siswa teladan. Namun pengambilan keputusan untuk memilih siswa teladan bukan atas kemampuan akademik dan non akademik, melaikan atas dasar subyektifitas kepala sekolah dan para guru terkait yang berbeda- beda sehingga memimucu komplik tentang keputusan tersebut atas dasar pemilihan siswa teladan yang kurang tepat sasaran. Oleh karena itu, proses pengambilan keputusan untuk memilih siswa teladan pihak sekolah saat ini kurang efektif didalam penentuan siswa teladan dikarenakan masih mengunakan proses untuk memilih siswa teladan itu berdasarkan bukan berdasaran kemampuan akademik dan non akademik.

Untuk mengatasi permasalahan tersebut penulis didalam melakukan penelitian ini, penulis ingin membuat solusi dari permasalahan yang dapat 
memudahkan pihak sekolah SMP Negeri 29 Padang dalam penentuan pemilihan siswa teladan dengan pemamfaatan metode Simple Additive Weight (SAW). Dan implementasi mengunan PHP Sehingga dapat membantu kinerja guru di SMP Negeri 29 Padang dalam penentuan siswa teladan .

\section{II.LANDASAN TEORI}

Metode Simple Additive Weight (SAW), Sering juga dikenal dengan istilah metode penjumlahan terbobot. Konsep dasar metode Simple Additive Weight (SAW) adalah mencari penjumlahan terbobot dari rating kinerja pada setiap alternatif pada semua atribut.

\section{III.METODE PENELITIAN}

\section{Metode}

Metode Simple Additive Weight (SAW)

metode yang sering dikenal dengan mentode penjumlahan terbobot. Maksud dari penjumlahan terbobot yaitu mencari penjumlahan terbobot dari rating di tiap alternatif pada seluruh atribut/ kriteria. Hasil/ Skor total yang diperoleh untuk sebuah alternatif yaitu dengan menjumlahkan semua hasil perkalian antara rating / yang dibandingkan pada lintas atribut dan bobot setiap atribut. Rating pada setiap atribut sebelumnya harus sudah melalui proses normalisasi.

Metode SAW memerlukan proses normalisasi matriks ke skala yang bisa dibandingkan dengan rating alternatif yang ada. Metode SAW dirumuskan dengan rumus berikut ini:

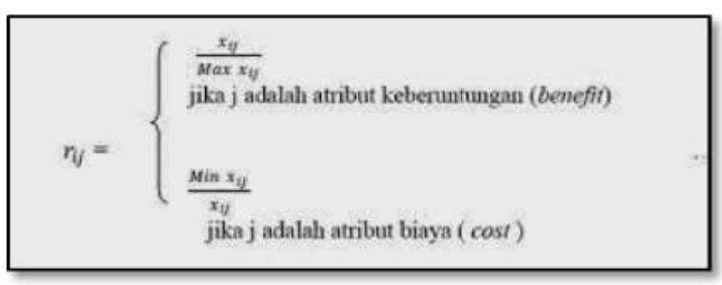

Dimana :

Rij $\quad=$ Rating kinerja ternormalisasi

Maxij = Nilai maksimum dari setiap baris dan kolom

Minij = Nilai minimum dari setiap baris dan kolom

$\mathrm{Xij}=$ Baris dan kolom dari matrik dengan Rij adalah Rating kinerja ternormalisasi dari alternative $\mathrm{Ai}$ pada atribut $\mathrm{Cj} ; \mathrm{i}=1,2 \ldots \mathrm{m}$ dan $\mathrm{j}=1,2, \ldots \mathrm{n}$

$$
\mathrm{V}_{\mathrm{i}}=\sum_{\mathrm{j}=1}^{\mathrm{n}} \mathrm{w}_{\mathrm{j}} \mathrm{r}_{\mathrm{ij}}
$$

Nilai Vi yang lebib besar mengindikasi bahwa alternatif Ai lebih terpilih Dimana : $\mathrm{Vi}=$ Nilai akhir dari alternatif $\mathrm{Wi}=$ Bobot yang telah ditentuan Rij $=$ Normalisasi Matriks Nilai yang lebih besar mengidikasi bahwa alternatif lebih terpilih. Metode Simple Additive Weigthing ( SAW ) disaranan untuk menyelesaikan masalah penyelesain dalam sistem pengambil keputusan multi proses. Metode Simple Additive Weigthing ( SAW ) merupakan metode yang banyak digunakan dalam pengambilan keputusan yang memiliki banyak atribut.

Ada beberapa langkah dalam penyelesaian metode Simple Additive Weigthing ( SAW ) adalah sebagai berikut :

1. Menentukan kriteria- kriteria yang dijadikan acuan dalam pendukung keputusan yaitu $\mathrm{Ci}$.

2. Menentukan rating kecocokan setiap akternatif pada setiap kriteria.

3. Membuat matriks berdasarkan kriteria ( Ci ).

4. Kemudian melakukan normalisasi matriks berdasarkan persamaan yang disesuaikan dengan jenis atribut ( atribut keuntungan 
maupun atribut biaya) sehingga diperoleh matriks ternormalisasi $\mathrm{R}$.

5. Hasil akhir diperoleh dari proses perangkingan yaitu penjumlahan dari perkalian matriks ternormalisasi $\mathrm{R}$ dengan vektor bobot sehinga diperoleh nilai terbesar yang dipilih sebagai alternatif terbaik ( A i) sebagai solusi.

Perhitungan dengan metode Simple Additive Weigthing ( SAW ) siswa teladan pada SMP Negeri 29 Padang dengan memperhatikan bebrapa kriteria penilaian.

Kriteria penilian tersebut antara lain :
a. Prestasi
b. Pengasilan Ortu
c. Jarak Tempuh
d. Nilai Ujian
e. Kerapian

1. Proses Perhitungan Simple Additive Weigthing ( SAW )

Sistem Pendukung keputusan penentuan siswa teladan pada SMP Negeri 29 Padang ini memiliki 5 kandidat siswa yang akan di nilai.
a. Nacita
b. Sri Mutiar
c. Randi setiawan
d. Andika
e. Dunan

Ada 5 Kriteria yang diinginkan :
1. Prestasi
2. Pengasilan Ortu
3. Jarak tempuh
4. Nilai ujian
5. Kerapian

Rangking kecocokan setiap alternatif pada setiap kriteria dinilai dari 1- 5 yaitu :

Sangat Kurang : 1

Kurang $: 2$

Cukup : 3

Baik : 4

Sangat Baik : 5

\section{Hasil Dan Pembahasan}

Tabel 1.Prestasi

\begin{tabular}{|l|c|l|l|}
\hline Harga ( C1 ) & Nilai & \multicolumn{2}{|l|}{ Keterangan } \\
\hline $\begin{array}{l}\text { Sangat } \\
\text { Kurang ( SK }\end{array}$ & 1 & Rangking > 20 \\
\hline Kurang ( K ) & 2 & $\begin{array}{l}\text { Rangking 15- } \\
20\end{array}$ \\
\hline Cukup ( C ) & 3 & $\begin{array}{l}\text { Rangking 10- } \\
15\end{array}$ \\
\hline Baik ( B ) & 4 & $\begin{array}{l}\text { Rangking 5- } \\
10\end{array}$ \\
\hline $\begin{array}{l}\text { Sangat Baik ( } \\
\text { SB ) }\end{array}$ & 5 & Rangking 1 - 3 \\
\hline
\end{tabular}

Tabel 2. Pengasilan Ortu

\begin{tabular}{|l|c|l|}
\hline $\begin{array}{l}\text { Kondisi ( C2 } \\
\text { Sangat }\end{array}$ & Nilai & Keterangan \\
\hline $\begin{array}{l}\text { Kurang ( SK } \\
\text { Kun. } 5.000 .000, .>\end{array}$ & 1 & Rp. \\
\hline Kurang ( K ) & 2 & $\begin{array}{l}\text { Rp. 4.000.000,.- } \\
\text { Rp. 5.000.000 }\end{array}$ \\
\hline Cukup ( C ) & 3 & $\begin{array}{l}\text { Rp. 3.000.000,.- } \\
\text { Rp. 3.000.000,. }\end{array}$ \\
\hline Baik ( B ) & 4 & $\begin{array}{l}\text { Rp.2.000.000,.- } \\
\text { Rp.3.000.000,. }\end{array}$ \\
\hline $\begin{array}{l}\text { Sangat Baik ( } \\
\text { SB ) }\end{array}$ & 5 & $<$ Rp.1.500.000,. \\
\hline
\end{tabular}

Tabel 3. Jarak Tempuh

\begin{tabular}{|l|c|l|}
\hline Daerah & Nilai & Keterangan \\
\hline $\begin{array}{l}\text { Sangat } \\
\text { Kurang ( SK }\end{array}$ & 1 & $<\mathbf{5}$ KM \\
\hline Kurang ( K ) & 2 & $5-10 \mathrm{KM}$ \\
\hline Cukup ( C ) & 3 & $10-15 \mathrm{KM}$ \\
\hline Baik ( B ) & 4 & $-20 \mathrm{KM}$ \\
\hline $\begin{array}{l}\text { Sangat Baik ( } \\
\text { SB ) }\end{array}$ & 5 & $20 \mathrm{KM}$ \\
\hline
\end{tabular}


Tabel 4 Nilai Ujian

\begin{tabular}{|l|c|l|}
\hline $\begin{array}{l}\text { Lingkungan ( } \\
\text { C4 ) }\end{array}$ & Nilai & Keterangan \\
\hline $\begin{array}{l}\text { Sangat Kurang } \\
\text { ( SK ) }\end{array}$ & 1 & $<50$ \\
\hline Kurang ( K ) & 2 & $50-65$ \\
\hline Cukup ( C) & 3 & $65-75$ \\
\hline Baik ( B ) & 4 & $75-85$ \\
\hline $\begin{array}{l}\text { Sangat Baik ( } \\
\text { SB ) }\end{array}$ & 5 & $85-100$ \\
\hline
\end{tabular}

Tabel 5 Keterampilan

\begin{tabular}{|l|c|l|}
\hline Akses ( C5) & Nilai & Keterangan \\
\hline $\begin{array}{l}\text { Sangat } \\
\text { Kurang ( } \\
\text { SK ) }\end{array}$ & 1 & Sangat Kurang \\
\hline $\begin{array}{l}\text { Kurang ( K } \\
\text { Cukup ( C) }\end{array}$ & 2 & Kurang \\
\hline Cukuk (B) & 4 & Cukup \\
\hline Baik ( Baik \\
\hline $\begin{array}{l}\text { Sangat Baik } \\
\text { (SB) }\end{array}$ & 5 & Sangat Baik \\
\hline
\end{tabular}

\begin{tabular}{|l|c|c|c|c|c|}
\hline \multirow{2}{*}{$\begin{array}{l}\text { Nam } \\
\text { a }\end{array}$} & $\begin{array}{l}\text { Kriteria } \\
\text { Pres } \\
\text { tasi }\end{array}$ & $\begin{array}{l}\text { Penga } \\
\text { silan }\end{array}$ & $\begin{array}{l}\text { Jar } \\
\text { ak }\end{array}$ & $\begin{array}{c}\text { Ni } \\
\text { lai } \\
\text { uji } \\
\text { an }\end{array}$ & $\begin{array}{c}\text { Ketera } \\
\text { mpilan }\end{array}$ \\
\hline $\begin{array}{l}\text { Nacit } \\
\text { a }\end{array}$ & 4 & 3 & 3 & 4 & 3 \\
\hline $\begin{array}{l}\text { Sri } \\
\text { Muti } \\
\text { ar }\end{array}$ & 5 & 4 & 2 & 4 & 4 \\
\hline $\begin{array}{l}\text { Rand } \\
\text { i } \\
\text { setia } \\
\text { wan }\end{array}$ & 2 & 3 & 2 & 3 & 5 \\
\hline $\begin{array}{l}\text { andi } \\
\text { ka }\end{array}$ & 4 & 3 & 5 & 4 & 2 \\
\hline $\begin{array}{l}\text { Duna } \\
\mathrm{n}\end{array}$ & 5 & 4 & 1 & 4 & 5 \\
\hline $\begin{array}{l}\text { Bobo } \\
\mathrm{t} \text { ( W } \\
\text { ) }\end{array}$ & 0,2 & 0,3 & 0,3 & 0,1 & 0.15 \\
\hline
\end{tabular}

Matrik Normalisasi ( R )

\begin{tabular}{|l|l|l|l|l|l|}
\hline & 0.800 & 0.750 & 0.600 & 1.000 & 0.600 \\
\hline & 1.000 & 1.000 & 0.400 & 1.000 & 0.800 \\
\hline$R$ & 0.400 & 0.750 & 0.400 & 0.750 & 1.000 \\
\hline & 0.800 & 0.750 & 1.000 & 1.000 & 0.400 \\
\hline & .1000 & 1.000 & 0.200 & 1.000 & 1.000 \\
\hline
\end{tabular}

Menentukan hasil dari perhitungan dengan metode SAW

$\mathrm{V} 1=(0.800 * 0.2)+(0.750 * 0.3)+($ $0.600 * 0.2)+(1.000 * 0.15)+($ $0.600 * 0.15$ )

$$
=0.74500
$$

$\mathrm{V} 2=(1.000 * 0.2)+(1.000 * 0.3)+($ $0.400 * 0.2)+(1.000 * 0.15)+($ $0.800 * 0.15$ )

$$
=0.85000
$$

$\mathrm{V} 3=(0.400 * 0.2)+(0.750 * 0.3)+($ $0.400 * 0.2)+(0.750 * 0.15)+(1.000 * 0.15$ )

$$
=0.64750
$$

$\mathrm{V} 4=(0.800 * 0.2)+(0.750 * 0.3)+$ $(1.000 * 0.2)+(1.000 * 0.15)+(0.400 *$ 0.15 )

$$
=0.79500
$$

$\mathrm{V} 5=(1.000 * 0.2)+(1.000 * 0.3)+($ $0.200 * 0.2)+(1.000 * 0.15)+(1000 * 0.15$ )

$$
=0.84000
$$

Rangking setiap Alternatif Dengan Metode SAW

\begin{tabular}{|c|l|l|}
\hline Nomor & \multicolumn{1}{|c|}{ Nama } & \multicolumn{1}{c|}{ Hasil } \\
\hline 1 & Nacita & 0.74500 \\
\hline 2 & Sri Mutiar & 0.85000 \\
\hline 3 & $\begin{array}{l}\text { Randi } \\
\text { Setiawan }\end{array}$ & 0.64750 \\
\hline 4 & Andika & 0.79500 \\
\hline 5 & Dunan & 0.84000 \\
\hline
\end{tabular}


Dari hasil analisa mengunakan metode Simple Additive weigting (SAW) dapat diketahui siswa teladan. Berdasarkan data yang ada pada tabel diatas.

\section{Tampilan Hasil Implementasi Mengunakan PHP}
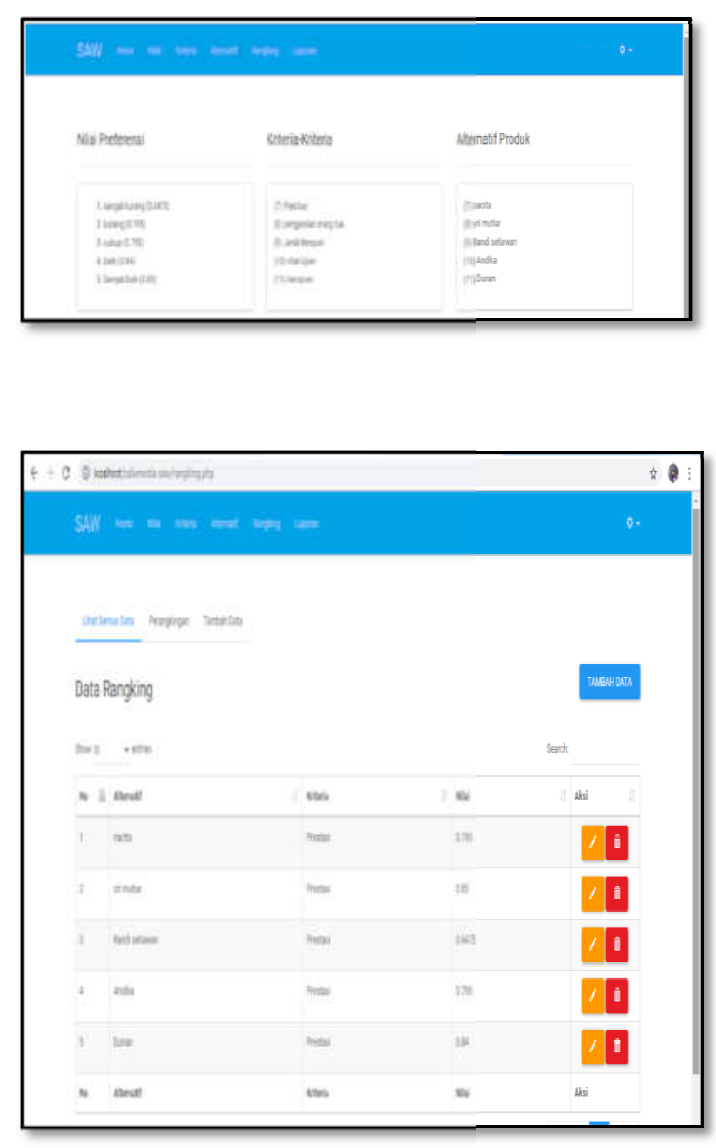

\section{IV.KESIMPULAN DAN SARAN}

\section{Kesimpulan}

Berdasarkan hasil Pemamfaatan Metode Simple Additive weigting (SAW) untuk sistem pendukung keputusan untuk menentukan siswa teladan. kesimpulan sebagai berikut:

1. Analisa mengunakan metode Simple Additive weigting (SAW) sehingga dapat memberikan kemudahan bagi guru disekolah .
2. Penerapan Metode Simple Additive weigting (SAW) untuk sistem pendukung keputusan dapat memberikan hasil yang maksimal dalam hal pengambilan keputusan dengan cara menentukan rengking kecocokan disetiap alternatif pada setiap kriteria.

Saran

Sistem ini belumlah sempurna sehingga membutuhkan pengembangan yang lebih lagi, adapun saran dari penulis yaitu :

1. Untuk pengembangan penelitian lebih lanjut maka sebaiknya dilakukan perbandingan metode atau penggabungan metode.

2. Sebaiknya dilakukan backup data secara berkala demi keamanan sistem ini.

\section{Daftar Pustaka}

1. Yusman, Yanti, Jurnal eDiKInformatika ISSN : 24070491 Volume 2 No 2, Maret 2015.

2. Kusumadewi, S., Hartati, S., Harjoko, A., Wardoyo, R. 2006. Fuzzy Multi Atribut Decision Making (FUZZY MADM), Graha Ilmu, Yogyakarta

3. Aulia Vitari, Said M. Hasibuan "Sistem Penunjang Keputusan Penerimaan Beasiswa Menggunakan Metode Analytical Hirearchy Process", KNS\&I, Bali, 2010

4. Pojoh, s, Lantang O. A,.\& Manembu, P.D.K ( 2016 ) Sistem Pendukung Keputusan Untuk menentukan Siswa Berprestasi Yang Layak Mwnjadi Siswa Teladan. 8(1). 